\title{
Research on Space Diagram Under Behavior Psychology in High Density Indoor Residential Environment*
}

\author{
Min Bao \\ Xi'an Siyuan University \\ Xi'an, China
}

\begin{abstract}
With the rapid development of urbanization and increase in city population, the high density indoor residential environment tends to be common in modern city life. When the population density in indoor residential environment is high, the people in crowded environment are liable to have special behavioral and psychological characteristics. To form the research of space diagram in high density indoor environment against behavior psychology characteristics through analysis of behavior psychology under high density residential environment, which include the causes and influential factors of behavior and psychology, space diagram design thinking reflected by behavior psychology, is of important significance for improving reasonable utilization of space and reducing negative influence on behavior psychology.
\end{abstract}

Keywords—high density; indoor residential environment; space diagram

\section{INTRODUCTION}

The existence of research on indoor residential environment has been for a long time. However, there are few studies on space diagram against high density indoor residential environment based on behavior and psychology. The key points studied in this paper include elaborating the behavioral and psychological characteristics under this indoor space using graphic design language, analyzing residential characteristics and demand of this group, solving the problems and disadvantages caused by space limitation, improving high density residential space environment, and shaping good life style. In the course of the research, the research basis is formed by virtue of accurate definitions of high density indoor residential environment and the space diagram of indoor residential environment, the influential causes and factors of behavior psychology is analyzed based on the above, and the spatial diagram thinking under behavior psychology in high density indoor residential environment is formed by combining with space diagram, to form design language for guiding the design of same type, so as to achieve the research purpose.

*Project No.: XASY-B1807, Project Name: Research on Application of Prefabricated Construction of Interior Decoration against Security Housing, Xi'an Siyuan University.

\section{RELEVANT DEFINITIONS AND ANALYSIS}

Indoor environment design is an important topic of human residential environmental research, the significant discipline to improve residential environment and to mould life style. The integration of multiple disciplines and multiple knowledge points has made the interior design not merely a single layer design by piling material up, furniture arrangement, especially the high density interior residential environment, and this special space type is short of the design language of psychology, function, intention and space. Therefore, the analysis of high density indoor residential environment and space diagram and the research on the influential factors of behavior psychology generated in high density indoor residential environment are the basis for reasonable design. As for the accurate definitions of high density indoor residential environment and interior space diagram, the analysis of the reasons of behavior and psychology generated in high density indoor residential environment is the important basis of research positioning, and the important link for the formation of design language.

\section{A. High Density Indoor Residential Environment}

High density indoor residential environment refers to the interior residential environment containing many people (more than 3), consisting of population of two generations or three generations, with the area per person of $10-15 \mathrm{~m} 2$. And it is characterized by low interior residential area per person, high residential density, and complex population structure and so on High density is the expression of the objective and actual status measurement of people's residential environment, including inside density and outside density. Inside density means the intensive degree of the number of people in each apartment or building; outside density refers to the quantity relationship among people, building and landscape outside the residential environment. Among them, the inside density relationship defined by number of people in each room can influence the interpersonal relation and behavior reaction more directly. The high density indoor residential environment is common in city life. There is certain difficulty in improving compartment size or number of people in the inside space, which is not applicable to all the families in real life. As a result, it is necessary to analyze the psychological and behavioral characteristics of people in high density indoor 
residential environment, to analyze and research based on space diagram, and to form the optimal high density indoor residential environment.

\section{B. Space Diagram of Indoor Residential Environment}

Space diagram is the expression of space formation, explanation of space, language of space design, fully reflecting the basic characteristics of space organization and space optimization. The space diagram of indoor residential environment takes diagram as its expression form, the behavior and psychology of people dwelling in the space as basis, and the process and regularity is formed by the indoor residential environment with functions such as dimension, order, grammar and significance, which are formed through overlaying of design elements, indoor space constitution and interior space combination. Analyzing the characteristics of behavior psychology and space behavior in combination with the behavioral and psychological characteristics in high density indoor residential environment to analyze space further, and analyzing the organization method through diagram relation are the design principles to be followed in designing high density indoor residential environment.

\section{Factors Influencing Behavior Psychology in High Density Indoor Environment}

By referring to high density residential interior environment, we will think of crowdedness first. During the period of 1960 s to early 1970 s, psychologist once conducted experimental research on high density influence on animal with mouse as the object. Limited residential space was provided for the mouse, and it was found through observation that at the early stage, the mouse started to establish their territory, mate, multiply and feed. With the increase in their quantity, the disorder and unusual behaviors of the mouse started to appear, reflecting in low birth rate, high death rate, killing their own kind and so on. Most female mouse did not play the role of protecting their territory and breeding, and most male mouse did not shoulder the task of breeding and nurturing. Psychologist Calhoun called such behavior as behavioral sink. Human will also be influenced by learning and cognition process, culture, personality, temperament and gender in addition to having same attribute with animals with respect to high density residential indoor environment. Therefore, the influence of high density residential indoor environment on human is more complex and variable. This shows that in the high density residential indoor environment without space diagram thinking, it is likely to appear the conditions such as self-development unbalance, disorder, abnormal behavior and psychology.

Take Chinese traditional rectangular courtyard as an example. The $1960 \mathrm{~s}$ to $1970 \mathrm{~s}$ witnessed an increase in population, multiple households or multiple generations lived in one courtyard, and the inside density and social density were enhanced obviously. Although households within the same yard can look after each other and it is convenient for children to play or rest, mutual association and talk, mutual interference among the neighbors and disputes among families are also particularly prominent. Compared with children living in low density family, the children living in high density family have poor task performance and control ability, showing more distinct acquired helplessness tendency. Relevant research of sociology also shows that the inside density is closely related to disease. Compared with residents living in low density indoor residential environment, residents living in high density indoor residential environment tend to seek medical advice more frequently. But no indication shows outside density is relating to disease, which is more caused by the influence of high inside density.

\section{FACTORS INFLUENCING BEHAVIOR PSYCHOLOGY IN HIGH DENSITY INDOOR RESIDENTIAL ENVIRONMENT}

Factors influencing behavior and psychology in high density indoor residential environment include individual difference of family members, setting conditions and the problem of interior space of the architecture itself. To analyze through influential factors is the necessary link of research.

\section{A. Individual Difference}

Individual difference is the important factor influencing behavioral and psychological difference, and it mainly consists of gender difference, personality and culture, life style difference, as well as adaption level. The irritation and restless of men in high density indoor residential space relate to animal's nature, as men are more of sense of territory, while women are more tolerate and can get on well with others. The inherent personality thinking that one can control his own fate is of more tolerance and inclusiveness towards high density indoor residential space than the external personality thinking things are controlled by external force. Similarly, people who have deep love for outdoor activities are easier to generate stress reaction towards crowded indoor environment than those prefer activities in indoor environment. People who live in high density indoor residential environment for a long time are apt to be suppressed in terms of their psychological behavior, and have more inclusiveness and tolerance towards space, but they still look forward to reasonable space distribution, and independent space in special circumstances.

\section{B. Setting Conditions}

The reaction caused by density influence is different in different living conditions, and it needs to be analyzed specifically. For instance, when a man is busy with working or learning, he needs independent individual space --- low decibel, no disturbance, and he will generate stress reaction and negative emotion if he is disturbed by other members. However, high density indoor residential environment can also intensity the atmosphere in certain circumstances, which is conductive to emotion expression. This is the "density --intensifying theory". For example, when the family members sit in the drawing room to watch TV programs together, they can communicate with each other, influence each other, generate same or similar favorites, and deepen the feelings.

\section{Interior Space Factors}

Indoor space factors are the factors affecting the building itself, the limitation conditions exist objectively. Square room appears to be more crowded than rectangle room when they 
have equal area, as longitude direction can stretch vision, extend sight, and form a sense of space expansion psychologically. The room with external vision seems to be more capacious than the room without such vision. External vision in indoor space is often reflected in balcony, French window or bay window connected to bedroom and drawing room, to guide people's sight. The sense of crowdedness can be reduced by improving brightness by adding appropriate light source on the wall or the hard decoration on the wall, such as wall lamp or spotlight. Similarly, the decoration materials with high reflection value of light also have the same function. The photos and mirrors on the wall can transfer vision and will also provide the sense of space expansion. To reduce the influence of high density indoor residential space on people's behavior psychology through these design methods is the main means of space diagram.

High density indoor residential environment will generate negative sense of crowdedness. Analyzing from the perspective of environment --- behavior relationship, there will be influence of three aspects, namely information overload, behavior restriction and eco-psychological reaction. The higher the density of indoor residential environment, the more the information will be generated. Moreover, it may influence people's freedom and behavior choice. For example, toilet is used frequently in the morning, and at this time behavior limitation will be generated. When too many people strive for limited resources, crowdedness will naturally appear.

Space separation is an effective means to reduce high density indoor residential environment. High density is a serious factor influencing indoor residential environment. A family is also a small society, and only when the family members do not disturb each other, ensure individual private space, the members have certain control ability, and take the characteristic space demand of each family member into account, can the harmonious and intimate family relation be established.

\section{MANIFESTATION OF SPACE DiAgRAM UnDER BEHAVIOR PSYCHOLOGY IN HIGH DENSITY INDOOR RESIDENTIAL ENVIRONMENT}

It is the emphasis of the research on space diagram under behavior psychology in high density indoor residential environment to manifest the relationship between space and space demand, behavior, make special effort to research how to use space more reasonably in high density indoor residential space environment, and analyze space diagram for individual space, interpersonal distance, privacy and indoor environment demand.

\section{A. Manifestation of Indoor Space Diagram for Individual Space and Interpersonal Distance}

In the indoor environment with many people live together, the distance, language, expression and gesture of people during their association play a subtle role. As a result, it is necessary to keep an appropriate distance and the intimate or independent space based on the relation attribute among the family members.
In the high density indoor residential environment, family members already have certain tolerance for space due to space limitation, but they still need certain individual space because of the influence of emotion, physical condition and behavior demand in family life. For example, when they are quarreling, writing homework, or working overtime. Individual space moves along with human body like an invisible, cone-shaped bubble, and it shrinks or expands in different situations. The influential factors include emotion, personality, age, gender, and environment, which are the minimum space required by individual psychology. When the individual space required by family members in their life, they will have some complex behavior reactions, such as changing face direction, adjusting chair angle, drawing back shoulders and elbows, supporting the jaw, isolating himself / herself using book or other objects, and even leaving. In this way, the affection between family members is affected.

In high density indoor residential environment, the space for working or learning should be reserved with an interval with drawing room and other rooms. If it is impossible to make an individual space, it should be placed at a L-shaped corner to form psychology supporting.

Normal Personal Distance for family members should be at least $0.45-1.2 \mathrm{~m}$, and $1.2-3.6 \mathrm{~m}$ for different space intervals should be guaranteed. The seat with concave-convex angles and curve space can stretch the space and improve relationship among family members, thus the atmosphere is made more relax.

\section{B. Manifestation of Private Indoor Space Diagram}

Privacy is the selective control of oneself or the group he/she belongs to. The privacy in high density indoor residential environment includes behavior tendency and psychological condition. Behavior tendency includes staying alone, getting well along with others closely, and avoiding others' interference. Information control refers to the individual conceals some things, and does not want to have too many exchanges and contact.

Privacy is helpful to establish self-identity, for instance, the perfect children space design is conductive for children's selfdefinition and self-cognition, so that they will not rely on others too much, thus form the ability of self-control, selfdiscipline and endurance. Parents entering children's room by knocking at the door first can offer children enough sense of respect. The visual exposure formed by sudden intrusion will bring about negative emotion due to privacy invasion.

Privacy is essential for ensuring family life harmony but does not very important; information control and staying alone are indispensable. Today, the high density indoor residential environment is more general in metropolises, and people in such cities face higher working pressure, living pressure and social pressure, so they need certain space to stay alone when they come back home. Good household environment should offer each family member their own individual space and private space of different levels. In the indoor space design, we can meet the demand by taking the design of privacy, semiprivacy and semi-publicity into account. 


\section{Manifestation of Space Diagram of Indoor Residential Environment}

The space diagram of indoor residential environment includes setting diagram, structure diagram and logic diagram.

The setting diagram is the manifestation of direct diagram of experienced scene, for example, in the daily life in indoor environment, we often carry out activities unconsciously, by the setting diagram analysis, we can analyze the scene following this action and the setting changes happen in usual conditions. Setting diagram contains and supports the conventional space diagram of our daily action. The streamline in indoor space can be designed by the research of setting diagram.

Structure diagram can transform the space elements, psychological behavior element and emotion elements into simple point and line to conduct analysis of connection, displacement, order, separation and concentration.

The multiple and multilayer analysis manifestation of high density indoor residential space with multi-limitation, multicharacteristic, personnel with multi-difference, multi-space attribute and multi-design elements is the spatiality owned by space diagram.

\section{CONCLUSION}

The space of high density indoor residential environment is of certain logic and diagram relation. The unique behavior difference and space demand concluded based on the behavior and mentality analysis under residential environment and elaborated using diagram language to form the unique design basis of high density indoor residential environment is an important breakthrough of the research in this paper.

\section{REFERENCES}

[1] Hiroshi Hara (Japan) Translated by Zhang Lun. Space --- From Function to Form [M]. Nanjing: Phoenix Science Press. 2017. 11. 原广 司 (日本) 张伦译. 空间一一从功能到形态 $[\mathrm{M}]$. 南京. 江苏凤凰科学 技术出版社.2017.11

[2] Hu Zhengfan, Lin Yulian. Environmental Psychology --- Environment, Behavior Study and Its Design Application (Third Edition) [M]. Beijing: China Architecture \& Building Press. 2012.10.1. 胡正凡、林玉莲.环境 心理学——环境、行为研究及其设计应用 (第三版) [M].北京. 中 国建筑工业出版社.2012.10.1

[3] Li Daozeng. Introduction to Environmental Behavior [M]. Beijing: Tsinghua University Press.1999.3.1. 李道增.环境行为学概论 [M].北京. 清华大学出版社.1999.3.1

[4] Li Haitao, Wang Zhenyu, Zhou Daocheng. Resident Behavior Demand and Residential Green Space [J]. City.1999.2. 李海涛、王振宇、周道 成. 居民行为需求与居住区绿地空间[J].城市.1999.2

[5] Chen Yang. Interior Environment and Structure Design [M].Xi'an. Xi'an Jiaotong University Press. 2002.1.P22-30. 陈洋.室内环境与构造 设计 $[\mathrm{M}]$.西安.西安交通大学出版社.2002.1.P22-30

[6] Zhang Jie. Application of Environmental Psychology in Interior Design [J].Kaifeng: Journal of Kaifeng University. 2009.6. 张杰. 环境心理学在 室内设计中的应用[J].开封.开封大学学报.2009.6. 